\title{
Solutions to the conundrum: I mplementing adult-gerontology graduate programs with current resources
}

\author{
Camille Payne ${ }^{1}$, Kathleen Farrell ${ }^{2}$
}

1. WellStar School of Nursing, Kennesaw State University, Kennesaw, Georgia, USA. 2. School of Nursing, Murray State University, Murray, Kentucky, USA.

Correspondence: Camille Payne. Address: WellStar School of Nursing, Kennesaw State University, Kennesaw GA, USA. Email: Ipayne3@kennesaw.edu

Received: February 14, 2014

Accepted: April 16, 2014

Online Published: May 27, 2014

DOI : $10.5430 /$ jnep.v4n8p44

URL: http://dx.doi.org/10.5430/jnep.v4n8p44

\section{Abstract}

Implementation of the Consensus Model has created new certifications and advanced practice nursing education programs. The combining or creation of new adult-gerontology programs prepares Advanced Practice Registered Nurses (APRNs) to care for the adult-gerontology population across the health spectrum of wellness to illness. As often occurs with legal or regulatory change, conundrums can develop for graduate nursing education programs during the implementation efforts as they struggle to meet the new requirements before needed resources are available. One of the most challenging problems has been developing the Adult-Gerontology population foci with available current resources. In order to address the conundrum, strategies need to be developed which will enhance graduate nursing education programs, create partnerships with practice and create service learning opportunities.

The change of preparing adult-gerontology APRNs capable of delivering care across the spectrum of wellness to illness in a variety of health care settings will eventually help address the needs of society, but there are barriers to the initial implementation which have to be overcome in order to achieve a successful long term solution to the nation's health care requirements. Formative strategies to effectively deal with the conundrums will keep the process of change moving forward. Working together collaboratively in a team approach will enable academia, practice, and the community to identify and bridge the hurdles to achieve success.

\section{Key words}

Advanced practice nursing, Adult-gerontology, Clinical practice, Nursing education

\section{Introduction}

Present and future health care needs in the United States (U.S.) have resulted in an immediate national priority for greater numbers of more highly educated advanced practice nurses. In The Future of Nursing: Leading Change, Advancing Health $^{[1,2]}$, the Institute of Medicine (IOM) clearly delivered the message that nurses should practice to the full extent of their education, training and competencies. With the Affordable Care Act (ACA) and a focus of U.S. health care shifting toward promoting wellness, preventing disease, and chronic disease management, the role that advanced practice registered nurses (APRNs) play in providing care is expected to increase. As key members of health care provider teams, 
the APRN contributions to the delivery of safe, high-quality, cost-effective, and patient-centered care can serve to improve access and availability to health care services. Barriers which are preventing APRNs from reaching their full practice potential need to be let down as the US health care system needs to be operating at full capacity ${ }^{[4]}$. The purpose of this paper is to identify and discuss barriers to implementation of full practice potential for advanced practice nurses. This paper also seeks to suggest strategies to address the education and practice conundrums which arise from the change in population focus to adult-gerontology.

Actualization of the full practice potential of APRNs will contribute to critical changes needed in health care reform, but will require a transformation of nursing practice. As the nursing profession evolves to meet the health care needs of society, stakeholders must employ strategies to effectively deal with the conundrums that are inevitable with rapid change. A proactive, collaborative approach using formative assessment methodologies during the implementation phases will identify problems and seek creative strategies to achieve a successful long term solution to the nation's health care requirements.

The development of the Adult-Gerontology population focus in which the APRN is responsible for patient care across the spectrum of health from wellness to acute care for the adult life span was one of the major dictates of the APRN Consensus Model regulations. Implementing the changes may be difficult to achieve with the current, available personnel and environmental resources of faculty, preceptors, and clinical sites. Clinical sites need to be expanded to include more than acute and primary care options to provide exposure to patients utilizing the wide spectrum of services addressing wellness to acute care; yet, these sites often have limited APRNs on staff. Until an adequate supply of Adult-Gerontology APRNs are educated and practicing in varied clinical sites, creative solutions are needed to provide the clinical experiences necessary to prepare qualified APRNs who are effectively socialized to the role.

\section{APRN consensus model}

The Consensus Model for APRN Regulation: Licensure, Accreditation, Certification \& Education (APRN Consensus Model) ${ }^{[3]}$ is a uniform model of regulation for the future of advanced practice nursing that is designed to align the interrelationships among licensure, accreditation, certification, and education (LACE). The APRN Consensus Model was created through a collaborative effort among more than 40 nursing organizations whose goal was to make APRN education and practice more uniform ${ }^{[5]}$. The APRN Consensus Model was designed to standardize, and thus elevate the role of APRNs and increase job satisfaction through opportunities to practice more independently and to the depth and extent of educational preparation.

The necessary coordination among licensure, accreditation, certification, and education bodies required by the APRN Consensus Model called for an incremental implementation process. The target date for full implementation of the APRN regulations across the four essential elements for licensure, accreditation, certification, and education is 2015. Although the model was completed in 2008, the effects on certification, and thus on graduate nursing education programs, are just beginning to take shape. Transparency and consistency of the new regulatory model will ultimately benefit the profession and improve patient care, however, both expected and unexpected challenges will emerge which require creative strategies to address. In particular, continued employment of the preceptor model will be difficult until sufficient numbers of adult-gerontology prepared APRNs have graduated, or until currently practicing APRNs have successfully broadened their skills to serve as effective preceptors. Further, organizations and agencies which are beginning to charge for APRN student assignments to preceptors further complicate continuation of the preceptor model, especially for programs with more limited financial resources.

The educational requirements of the new APRN Consensus Model stipulate graduation from a nationally accredited graduate level program. The graduate is prepared in one of the four APRN roles: Nurse Practitioner, Nurse Midwife, Nurse Anesthetist or Clinical Nurse Specialist. The programs prepare the graduate in at least one of the six population foci: 
Family/Individual Across life span, Adult-Gerontology, Neonatal, Pediatrics, Women's Health/Gender Related, or Psychiatric/Mental health. Three separate and broad-based graduate-level courses in advanced physiology/ pathophysiology, advanced health assessment, and advanced pharmacology must be included in the APRN course work. The academic program must include a minimum of 500 faculty-supervised clinical hours in the focal role and population.

As implementation of the APRN Consensus Model is phased in, academic institutions have joined existing programs, or developed new graduate programs. Professional organizations that include the American Association of Colleges of Nursing (AACN), the Hartford Institute for Geriatric Nursing at New York University, National Organization of Nurse Practitioner Faculties (NONPF) ${ }^{[5]}$, and the National Association of Clinical Nurse Specialist (NACNS) ${ }^{[7]}$ have developed and released competencies for Adult/Gerontology APRN programs. The American Nurses Credentialing Center (ANCC) has initiated plans to change specific certification programs to more closely reflect the roles and populations required by the model regulations.

\section{Preceptor model}

In the majority of current graduate clinical nursing education programs, students are assigned to a preceptor for guided, mentored practice for one-on-one clinical experiences in the health care setting. Each student receives individual attention and guidance from the preceptor. This model permits an opportunity for students to apply newly acquired knowledge to real clinical situations which facilitate the development of clinical reasoning skills ${ }^{[8]}$. Experiential learning is a key ingredient in APRN education, allowing the learner to make meaning of experiences and also permitting socialization into the APRN role to occur. The reliance on the preceptor model in graduate nursing education has been demonstrated to be a valuable teaching strategy to foster learning ${ }^{[8]}$. Students benefit from engagement in practice, participation in clinical decision-making processes, prompt constructive feedback and learning in a 'relatively safe' environment that allows them to fine tune their skills under preceptor tutelage ${ }^{[9]}$.

As there are not yet sufficient numbers of adult-gerontology APRNs to serve as preceptors for advanced practice nursing students, this current serious shortage of APRNs also means an inability to meet the health care requirements of the adult-gerontology population. Under the best circumstances, there are not always enough APRNs at approved clinical sites who are willing or available to serve as preceptors, and many programs have a preceptor shortage. The shortage is particularly acute now as the change is being implemented before there are adequate numbers of adult-gerontology APRNs graduated and practicing with the competent clinical experience necessary to serve as adult-gerontology preceptors. As APRN programs strive to meet the demand by increasing enrollment numbers, it is essential that clinical sites and APRNs in practice become engaged in educating the growing number of students to meet domestic and global health care needs for aging populations ${ }^{[10]}$. The demand for quality health care providers, faculty and preceptors significantly outweighs the current and near future supply. This is an acute issue for graduate clinical nursing education programs due to the implementation of the new programs focused on the adult-gerontology population. There is a great need to educate more APRNs who can provide adult-gerontology care in varied health care settings, but this requires that education programs have the faculty expertise, are able to admit students to these programs, and have clinical sites and preceptors available to provide clinical experiences. Contracted clinical sites with APRN preceptors across the continuum of care (wellness to acute care in-patient and outpatient facilities) are needed to provide varied experiences. These clinical sites may offer experiential learning; however, few of them employ APRNs. The combination of additional strategies to be used in conjunction with the preceptor model and varied use of clinical sites will help to ensure adequate education of the adult-gerontology APRN.

The curricular guidelines and expectations for addressing adult-gerontology patient care needs will be particularly challenging for graduate nursing programs to continue utilization of the preceptor model for clinical experiences. Advanced practice nurse preceptors without formal education or experience in gerontology content may need support in broadening the approach and scope of practice used to precept adult/gerontology advanced practice students. Thornlow et 
al. ${ }^{[11]}$ identify that without a sufficient number of advanced practice nurses prepared in gerontology our nation is "woefully underprepared to address the complex health care needs of older adults" (p. 116). It is also significant to note that most nurses find themselves caring for older adults regardless of the care setting ${ }^{[12]}$.

These challenges provide an excellent opportunity for academia to promote collaborative experiences for students, faculty, clinical preceptors, other health care providers and related agencies to work together to provide strengthened adult-gerontology content and resources in order to ensure quality patient care and clinical practice. Further, these challenges provide multiple opportunities for education to "pay back" their associated clinical agencies for the investment of preceptor time through collaborative opportunities which strengthen gerontological learning experiences for all stakeholders. An investment of understanding of the collaborative relationship between practice and education is required. Often, educational program changes must be made with existing resources. The development of a community collaborative effort can serve to assist current APRNs to enhance gerontological practice skills to improve readiness and ability to serve as preceptors for adult-gerontology students, provide APRN students with unique opportunities, and serve to coordinate existing community services.

\section{Strategies and suggestions}

The following sections highlight strategies and suggestions for collaborative efforts and projects designed not only for programs to address curricular and regulatory guidelines, but also as mechanisms to enhance gerontology learning opportunities for APRN preceptors, nursing staff, and other agency personnel. While the process of curricular redesign or enhancement can be quite intense and laborious, Holody and Kolb ${ }^{[13]}$ described strong faculty commitment to effective enrichment of existing curricula, rather than changing the entire curriculum. Gerontology content can be enhanced through infusion of new material and resources in fresh and unexpected ways ${ }^{[14-17]}$.

\subsection{Program strategies to enhance community collaboration}

Program strategies which support and provide reciprocal opportunities for stakeholders for collaboration, as well as identification of existing and needed resources in the community, allows for access to a greater consortium of resources. Ansari and Phillips ${ }^{[17]}$ noted that a successful collaboration enables members to collectively meet needs and goals, create longevity and gain recognition. Holody and Kolb ${ }^{[13]}$ posited that the participation of stakeholders from beyond academia created new ideas and perspectives. Community partners can identify resources which they may be able to make available to the nursing program, and the program in turn, may be able to identify available resources for the community.

Clearly, the initial step in community collaboration is for the nursing program to seek and develop strong relationships with community agencies, institutions, individuals and other essential resources as a part of establishing a strong network for educating advanced practice nurses and strengthening available services in the community. The creation of a network of excellence ${ }^{[12]}$ benefits the greater community which shares in the provision of care to older adults. The successful development of partnerships within the community establishes mutual exchange and commitment, and provides an ongoing forum for collaborative learning among all stakeholders.

\subsubsection{Community stakeholder council}

Essential links to the greater community of interest can be a critically important component to establish and effectively promote adult/gerontology interprofessional engagement. Faculty can participate in the identification of important stakeholders, such as local health care agencies, nursing or medical organizations, or long term care facilities, which will help to ensure a broad range of diverse community participants, and to strengthen faculty investiture in the process ${ }^{[13]}$. Effective interprofessional coalitions need to establish "a vital sense of ownership” (p. 353) for all involved parties ${ }^{\text {[17] }}$. Further, inclusion of older adult consumers from within the community establishes a direct link to the population of interest, and can help to identify and impact community needs and opportunities for further development of the stakeholder council. 
Both accrediting bodies for nursing programs describe the expectation of active participation of the communities of interest in program processes. The Accreditation Commission for Education in Nursing, Inc. (ACEN) ${ }^{[18]}$, and the Commission on Collegiate Education in Nursing (CCNE) ${ }^{[19]}$ relate inclusion of the community of interest in the first standards of accreditation, as well as in successive standards. Communities of interest are expected to participate in the program processes, including mission, goals and expected outcomes for students and program. Participation and inclusion of the greater body of the community of interest in the stakeholder council provides a real and direct consonance with the definition and intent established by the accrediting nursing organizations.

Kennedy-Malone et al. ${ }^{[12]}$ described a coalition composed of nurses from multiple gerontological health care agencies, including long term care, acute care, home nursing, and undergraduate nursing programs. The coalition served primarily to assess geriatric nursing community needs, and to provide a mechanism for nurses to participate in continuing education. Holody and Kolb ${ }^{[13]}$ identified that the participation of the stakeholders resulted in significant generation of ideas and differing perspectives, which served to reinforce faculty commitment to the project.

The community stakeholder council can help to identify experiential learning projects based on the suggestions described in the sections below, or according to their own clinical needs or experiences. Success of the council will in part be dependent on all members approaching with the primary goal of mutually ensuring expert and effective care of older adults. Recognition of each stakeholder as a valuable component of a coordinated, collaborative effort to improve care for older adults will serve as an effective goal for binding relationships.

\subsubsection{Website repository for resources}

Developing a website repository dedicated to gerontological nursing resources will be extremely beneficial to nursing programs and healthcare agencies. The website can feature links to existing national and international resources; local, regional, national or international known of initiatives; tools and instruments for use with older adult populations; as well as other documents identified as valuable and useful by the council members. Geriatric nursing initiatives of the nursing program, or the community stakeholders, can be showcased ${ }^{[12]}$.

Gerontology Learning Modules for self-paced individual instruction can be a valuable resource for multiple initiatives ${ }^{[11]}$. Modules can be developed as an individual resource for new full or part-time clinical faculty to enhance and update knowledge, as a mechanism for self-paced continuing education offerings, or in preparation for mentoring or precepting advanced practice students. As a provision for continuing education, the modules can be an avenue for practicing APRNs to meet ongoing certification requirements, as well as providing a means for enhancing knowledge of care for gerontologic patients. Further, continuing education offerings can be developed as a revenue enhancement for programs.

\subsubsection{Gerontology resource library}

As a means of strengthening scarce resources, nursing program and community participants can identify and build available resources which support gerontological education. The library can include a cooperative listing and location of printed media, film and other digital resources. Available librarians at colleges, universities, or in larger health care agencies are often willing to provide invaluable assistance in the identification of resources ${ }^{[12]}$. While it may not be practical or possible to house materials in a single location, an easily accessible listing of identification and location of available resources will reduce the time and frustration for all gerontological education participants.

\subsection{Student assignments for strategic enhancement of preceptor knowledge and skills}

In addition to program strategies to enhance community collaboration and engagement, specific student assignments can be employed which will serve the dual purpose of providing educational experiences in gerontologic content for advanced practice nursing students engaged in clinical practice and will provide similar opportunities for preceptors, registered 
nurses and other staff in the patient care area. APRN students and faculty should work carefully with preceptors to identify teaching and learning needs designed to improve the care of older adults.

\subsubsection{Service learning}

Service learning provides an opportunity for APRN students to participate in actual, experiential service projects which benefit both the student and the community. Service learning has gained wide popularity in education environments, and is generally considered to be comprised of four components: direct engagement in community, reciprocal learning by all involved stakeholders, critical reflection of the students, and involvement and emphasis on community needs ${ }^{[20,21]}$. In a qualitative study designed to explore the lived experience of nursing student in service learning, Hunt ${ }^{[22]}$ described themes related to service learning as both an eye opening experience, and as having the ability to challenge and transform assumptions, perceptions and stereotypes. Service learning as a concept has unlimited potential for deep community collaboration and engagement for nursing programs and APRN students in real time learning experiences which can impact and strengthen individual and collective community members. Through service learning, APRN students become an active part of the health care team, and are less likely to be viewed as one-dimensional burdens.

Service learning projects could include any project which provides service to the community members, collectively or individually, and is a part of an expected course requirement. Examples might include community events such as health fairs or scheduled education sessions in community centers or similar setting. The planning and implementation will connect the students deeply within the community and provide a needed service.

Ross ${ }^{[21]}$ describes service learning in an undergraduate gerontology nursing course with the primary goal of facilitation of student understanding of older persons and their unique needs. Ross stated that nursing students "interact with older adults along a continuum ranging from well elders to nursing home residents” (p. 54). Service learning benefits students through direct involvement with the community, the academic institution through enhancement of community contacts and collaboration, and the community agency through the opportunity for participation in teaching and the assistance provided by the APRN students ${ }^{[21]}$.

\subsubsection{Evidence-based practice and research activities}

Knowledge and skills related to current gerontologic practice can be further developed or enhanced through project engagement of APRN students in directed research studies or evidence based practice projects. Gerontological content can be enhanced through identification of specific research opportunities in selected agency sites, as well as APRN student presentation of evidence based projects identified by needs assessments or preceptor requests.

Research assignments such as critiques can be selected and designated from gerontological research studies ${ }^{[16]}$. As students progress in courses, gerontology competencies can be explored through research based assignments such as evidence-based practice projects, as well as emphasizing and demonstrating both the application of evidence based plans of care and outcome driven care ${ }^{[14]}$. Research projects are another example and could include either directed research studies or evidence based practice examples.

The design and implementation of projects which result in the development of models of care for common health concerns of older adults can be extremely valuable to health care agencies. As the APRN student and preceptor work together, the student is exposed to the effectiveness of collaborative influence and engagement to create planned change. Models can be related to overall geriatric concerns or specific components of geriatric care based on common concerns such as access to care, safety, skin care, nutrition and dementia management ${ }^{[14,15]}$.

\subsubsection{Policy and procedure updates}

One of the ways in which APRN students can contribute to advancing agency care for older adults is through targeted review of policies and procedures. Through defined projects, such as reviews in health care policy courses, or evidence based practice models, APRN students can be assigned to work with their preceptors to identify policies or procedures in 
need of review or update related to the care of older adults. Influencing public policies which are aimed at the prevention and reduction of risk for functional decline can be a leading role component for APRN students ${ }^{[14]}$. For example, a student assignment which includes a policy analysis with an extensive literature review, can then be shared with the preceptor and clinical agency. In this way the assignment meets student learning needs, but also provides a return on preceptor's investment of time through updated materials and resources which save valuable time for the preceptor and agency, and can contribute to improving adult-gerontological care.

\subsubsection{Clinical rounds}

Clinical rounds are a long established means of enhancing the process of clinical decision making for health professions students. Perry \& Paterson ${ }^{[23]}$ describe clinical rounds as an effective pedagogical strategy in the clinical setting for undergraduate nursing students. Easily adaptable as a learning strategy for APRN students, clinical rounds can be focused on specific conditions or diagnoses, or on direct aspects of geriatric care. Students can work with preceptors to assess and identify and target learning needs of nursing and ancillary staff. Further, clinical rounds can provide a mechanism for developing coordinated undergraduate and graduate nursing student assignments, as well as opportunities for interprofessional collaboration.

\subsubsection{Case studies}

Case studies can be used effectively to highlight a variety of issues related to care of older adults ${ }^{[15]}$. Thornlow et al. ${ }^{\text {[10] }}$ discuss a model and template for developing and using case studies in the focused integration of gerontological content.

Case study development can be expanded to produce gerontological vignettes. Vignettes can be added to the previously discussed website or library materials to increase available materials, or to focus on a specific situation related to care of the older adult. Vignettes can be particularly useful for practice faculty whose teaching is informed by their own clinical experiences $^{[13]}$.

\section{Conclusion}

Major changes in foci of health care systems, including the attempts to actualize the full practice potential of APRNs, have required transformation of nursing practice and graduate nursing education programs to prepare future APRNs. The APRN Consensus Model has dictated a major paradigm shift in nursing education and practice. Conundrums have occurred during the implementation efforts, as problems with implementation are identified. The implementation of the APRN Consensus Model with the development of the Adult-Gerontology population focus in which the APRN is responsible for patient care across the adult life has created the need for graduate nursing education programs to make strategic changes with the current resources available. The strategies presented and discussed will enhance graduate nursing education programs through partnering with practice, and creating service learning opportunities. Preparing adult-gerontology APRNs for care delivery in a variety of health care settings will begin to address and provide solutions for the needs of society and create successful long term solutions to the nation's health care requirements. Working together in a team approach will enable academia, practice and communities to bridge the hurdles and achieve success.

\section{References}

[1] Institute of Medicine. The Future of Nursing: Leading Change, Advancing Health. Washington, DC: The National Academies Press. 2010. Available from: http://futureofnursing.org.

[2] Institute of Medicine. The Future of Nursing: Focus on Scope of Practice. 2011. Washington D.C.: The National Academies Press. Available from:

http://www.iom.edu/Reports/2010/The-Future-of-Nursing-Leading-Change-Advancing-Health/Report-brief-Scope-of-Practice.a spx. 
[3] APRN Consensus Work Group and the National Council of State Boards of Nursing APRN Advisory Committee. The Consensus Model for APRN Reculation, Licensure, Accreditation, Certification and Education. 2008. Available from: https://www.ncsbn.org/4213.htm

[4] Kunic RJ, Jackson, D. Transforming nursing practice: Barriers and solutions. AORN Jrnl. 2013; 98: 236-245. http://dx.doi.org/10.1016/j.aorn.2013.07.003.

[5] American Nurses Credentialing Center. APRN corner: Frequently asked questions. 2013. Available from: http://www.nursecredentialing.org/Certification/APRNCorner/APRN-FAQ\#Q5.

[6] National Organization of Nurse Practitioner Faculty. Adult-Gerontology Primary Care Nurse Practitioner Competencies. 2010. Available from: http://www.noAPRNf.com/associations/10789/files/Adult-GeroACCompsFinal2012.pdf.

[7] National Association of Clinical Nurse Specialists. Adult-Gerontology Clinical Nurse Specialist Competencies. 2010, March. Retrieved from: http://www.nacns.org/docs/adultgeroCNScomp.pdf.

[8] Billay D, Myrick F. Preceptorship: An integrative review of the literature. Nurse Education in Practice. 2008 ; 8: $258-266$. PMid:17988946 http://dx.doi.org/10.1016/j.nepr.2007.09.005

[9] Jordan R, Farley CL. The confidence to practice midwifery: Preceptor influence on student self-efficacy. Journal of Midwifery and Women’s Health. 2008; 53(5): 413-420. PMid:18761294 http://dx.doi.org/10.1016/j.jmwh.2008.05.001

[10] American Association of Colleges of Nursing (AACN), in collaboration with The Hartford Institute for Geriatric Nursing at New York University, and the National Association of Clinical Nurse Specialist (NACNS). 2005. Competencies for Adult/Gerontology Clinical Nurse Specialist. Available from: http://www.nacns.org/docs/adultgeroCNScomp.pdf.

[11] Thornlow D K, Auerhahn C, Stanley J. A necessity not a luxury: Preparing advanced practice nurses to care for older adults. Journal of Professional Nursing. 2006; 22(2): 116-122. PMid:16564478 http://dx.doi.org/10.1016/j.profnurs.2006.01.015

[12] Kennedy-Malone L, Penrod J, Kohlenberg EM, Letvak SA, Crane PB, Tesh, A, Kolanowski A, Hupcey J, Milone-Nuzzo P, Integrating Gerontology Competencies Into Graduate Nursing Programs Journal of Professional Nursing. 2006; 22(2): 123-128. PMid:16564479 http://dx.doi.org/10.1016/j.profnurs.2006.01.010

[13] Holody R, Kolb P. 10 Steps to sustain infusion of gerontology across the social work curriculum. Educational Gerontology. 2011; 37: 791-808. http://dx.doi.org/10.1080/03601271003780974

[14] Conley DM, Burkey TL, Schumacher S, Lyons D, DeRosa SE, Schirm V. Implementing geriatric models of care: A role of the gerontological clinical nurse specialist—part I. Geriatric Nursing. 2012; 3(3): 229-234. http://dx.doi.org/10.1016/j.gerinurse.2012.03.009

[15] Conley DM, Burkey TL, Schumacher S, Lyons D, DeRosa SE, Schirm V. Implementing geriatric models of care: A role of the gerontological clinical nurse specialist_part II. Geriatric Nursing. 2012; 3(4): 314-318. http://dx.doi.org/10.1016/j.gerinurse.2012.06.005

[16] Kohlenberg E, Kennedy-Malone L, CraneP, Letvak S. Infusing gerontological nursing content into advanced practice nursing education. Nursing Outlook. 2007; 55: 38-43. PMid:17289466 http://dx.doi.org/10.1016/j.outlook.2006.09.006

[17] Ansari WE, Phillips CJ. Interprofessional collaboration: A stakeholder approach to evaluation of voluntary participation in community partnerships. Journal of Interprofessional Care. 2001; 15(4): 351-368. http://dx.doi.org/10.1080/13561820120080481

[18] Accreditation Commission for Education in Nursing, Inc. 2013. Guidelines for the preparation of the self-study report utilizing the 2013 ACEN standards and criteria. (Author): Atlanta GA.

[19] Commission on Collegiate Education in Nursing. 2013. Standards for Accreditation of Baccalaureate and Graduate Nursing Programs, Amended 2013. Commission on Collegiate Education in Nursing: Washington, DC.

[20] Hoebeke R, McCullough J, Cagle L, St. Clair J. Service learning education and practice partnerships in maternal-infant health. JOGNN. 2009; 38: 632-639. PMid:19883486 http://dx.doi.org/10.1111/j.1552-6909.2009.01062.x

[21] Ross MET. Linking classroom learning to the community through service learning. Journal of Community Health Nursing. 2012; 29: 53-60. PMid:22313185 http://dx.doi.org/10.1080/07370016.2012.645746

[22] Hunt, R. (2007). Service-learning: An eye-opening experience that provokes emotion and challenges stereotypes. Journal of Nursing Education. 2007; 46 (6): 277-281. PMid:17580740

[23] Perry, J. \& Paterson, B.L. Nursing rounds as a pedagogical strategy: Anchoring theory to practice in gerontological nursing. Nurse Education in Practice. 2004; 5: 63-69. PMid:19038181 http://dx.doi.org/10.1016/j.nepr.2004.03.001 